\title{
Reforms on teaching of mathematical modeling and organization of contest
}

\author{
Qi Qiang Yang * \\ Department of Mathematics, Qiongzhou College, Sanya, China \\ keeponmoving@126.com
}

Keywords: Mathematical modeling; Teaching; Contest; Undergraduate; Reform

\begin{abstract}
With rapid delvelopment and popularization of high-tech and computer, the importance of mathematics becomse increasingly prominent. Human has entered the society of information and the era of network, which makes the mode of mathematical education changing. Mathmatical modeling is the best joint of improving mathematical knowledge and application abilities. The teaching of mathematical modeling is an important way to carry out qualitative education while China Undergraduate Mathematical Contest in Modeling is an incentive to attract students to attach importance to mathematical modeling. Mathematical modeling teaching and organizaing students to participite in the contest is not only an important way to inspire innovative consciousness, increase innovative ability, cultivate high level talents but also an effective measure to inspire students' learning desire, foster spirit of active exploration and striving to forge ahead. There exists some experiences and problems in the author's college in mathematical teaching and organization of the contest. They are discussed to find out an efficient scheme of cultivation that could be utilized to cultivate qualified talents in future.
\end{abstract}

\section{Introduction}

Mathematics comes from man's social practice, for example, industrial and agricultural production, commercial activities, military operations and scientific and technological researches. And in turn, mathematics serves the practice and plays a great role in all fields. No modern scientific and technological branches could be regularly developed without the application of mathematics. As the information developing rapidly, Mathematics as highly abstract and rigorous logic discipline, has penetrated into various fields from natural science to social science, play a more and more important even decisive role. The combination of Mathematics and computer technology makes the Mathematics practical. To play the role of mathematics, various problems on study are attributed to a corresponding mathematical problem, namely mathematical models are established for the problems, it is possible on this basis to utilize mathematical theories and methods to analyze and study the problem thoroughly so as to provide accurate data and reliable guidance for solving practical problems [1-5]. Therefore, the consciousness and ability of building mathematical modeling is the basic quality of contemporary persons who purse the work of science and technology. Mathematical modeling has injected great vitality for mathematics education and is a necessary way to enlighten mathematical mind [6].

China Undergraduate Mathematical Contest in Modeling as annual session, founded in 1992, has became the basic subject competition with the largest national college scale. In 2014, more than 70000 students are enrolled in the contest [7]. As the national undergraduate Mathematical contest in Modeling is carried out widely, mathematical modeling curriculum is allowed in more and more majors. Mathematical modeling curriculum can develop the students' ability to use mathematical knowledge to analyze and solve practical problems and cultivate the consciousness, thinking and ability of innovative consciousness. The setting up of Mathematical modeling course is an effective measure to inspire students' learning desire and to foster spirit of active exploration, striving to forge ahead and cooperating with the team numbers. Those in other majors who have been trained for the contest also benefit much. Their abilities of self-learning are strengthened and interests of learning are 
improved. They can complete their graduate paper design with ease. In future work the experiences, application abilities and logic reasoning abilities they possess would help them to handle affairs free and relaxed. Many scholars have explored how to teach with mathematical modeling thinking in professional teaching [8-10]. In this paper, we start with the discussion of the problems of mathematical modeling teaching. Next, problems confronted in the organization of the contest are discussed. Finally, a conclusion is made.

\section{Teaching of mathematical modeling course}

The mathematical modeling course has been set up for many years for the students whose major is mathematics and applied mathematics. Currently, the course is arranged in the fifth semester, totally 90 hours. The relative courses that have been set up previously include mathematical analysis, higher algebra, probability theory and mathematical statistics, differential equations. Other relative courses relative to mathematical modeling include mathematical software, linear programming, discrete mathematics, combinational mathematics, graph theory and literature retrieval and paper writing, which are set up subsequently. The arrangement has many merits, for example, the basic knowledge has been prepared before the setting up of mathematical modeling, consequently, the teaching of mathematical modeling becomes unhindered. However, the arrangement needs to be improved. First, it would be more appropriate to put the course in the fourth semester. In this way, the students would be more competent later in the contest in the fifth semester after the learning of course. Otherwise, it would be a pity that they only can participate in the contest once after the learning of the course. Second, the setting up of relative courses is somewhat improper. It is proper to set up mathematical software course in the second semester, since they have a certain understanding ability of computer language after the learning of windows culture basis in the first term and can grasp the elementary operations of mathematical software. Similarly, it is more proper to put the reference retrieval and paper writing course in the second semester since the course needs no preparation of knowledge. Some other courses such as discrete mathematics, combinational mathematics can also be setting up in advance. Third, relative courses are insufficient, numerical calculation is not setting up, for the optimization module only linear programming is setting up without integer programming, nonlinear programming, dynamic programming or operational research. Discrete mathematics, combinational mathematics as electives may not be opened.

For the organization of teaching, 36 hours are for classroom teaching and 54 hours for experiment teaching, i.e., most classes are taken in the computer room, which is irrational. Computational operation is just a step of implementing mathematical modeling and should not consume so much teaching time. The most important part is to analyze and formulate the problem rather than the final implementation. After the model is built, working out how to solve it is also important than the computational operations. Too much time is taken in the experimental teaching leads to that less contents are taught, which cause the teaching effect to decline. Thus, the time distribution needs to be adjusted. More time is allocated to classroom teaching so as to cultivate students the ability of analyzing problems in classroom and exercise their ability of solving problems in the study of more modules.

For the selection of teaching material, the one who takes the course in hand chooses one textbook at will. The importance of textbook has been neglected. A good textbook may have moderate contents, be written clearly in popular and easy-to-understand language, is so important, make the teaching and learning relatively simple. Besides, a good mathematical modeling textbook should focus on the analysis of problems and be illuminating. Thus, the textbook should be selected carefully from so many textbooks by all relative teachers.

For the interior teaching communications, only two teachers teach mathematical modeling course and one is the alternate of the other, they never communicate on the teaching. On the other hand, mathematical modeling is only one of applied courses and not much care is paid, the professor never communicates with other teachers of relative courses. A preferred option is that teachers who teach 
relative courses are grouped to teach the mathematical modeling course alternatively. They should discuss the teaching methods of mathematical modeling and other relative courses ordinarily. Mathematical modeling is not an isolated course, moreover, the cultivation of ability in modeling can not rely the mathematical modeling teaching. In the teaching of various relative courses, much attention should be paid to foster the students' idea of modeling, encourage them to think, and guide them to solve problems.

For the external teaching communications, only two certain teachers who go to mark the contest papers have a little opportunities to exchange ideas. No one has been sent out to participite conferences about mathematical modeling or study further on the teaching methods and contest training. To grasp the tendency of mathematical modeling and learn advanced teaching methods, some teachers should be sent out to study further.

For the teaching mode, we just lay stress on the classroom teaching and remedial teaching before the contest without paying attention to extra-curricular teaching. There is a nominally mathematical modeling group with no group activities. After classes, the supervision and guidance of mathematical modeling group activities need to be strengthened. Seminars, interesting problem discussions, various mathematical contests including college ranked mathematical modeling contests should be conducted. Let some excellent students participate in the research projects of teachers. Through various forms of assistant forms, the students are trained, their knowledge is extended, their interests and uplifting spirits are stimulated.

For the setting up of mathematical modeling course in the author's college, each major itself decides whether to set up. At present, the majors setting up the course are not too many. The fostering of ability of mathematical modeling for other majorities relies on the teaching of common required courses, such as higher mathematics, linear algebra and probabilities. Besides, we can set up mathematical modeling as a public elective course to cultivate more students in the ability of mathematical modeling.

\section{Organization of mathematical contest in modeling}

We have organized students in group to participate the National Undergraduate Mathematical Contest in modeling for many years. During the past fiver years, two teams have won the national first prize, five teamns have won the national second prize. Excellent results are obtained. In this regard, we obtain some experience. In view of current problems, we will further put forward the reform schemes.

For the players selection, we take the form of voluntary registration of students. Those interested in the contest are all allowed to participate. It also produces some side effects. Some students harbor the lucky psychology for the winning a prize and make little efforts to improve themselves. And along with the trend of competition gets more and more strong, it is necessary to incorporate some competent students in and exclude those sluggards. After their registration, a simple test is required to eliminate some unqualified students. However, how and what to test effectively and impartially need to be studied further. Some aspects we are considering include middle school Olympic competition problems, basic knowledge of difference and calculus, basic software fundamentals, the ability of reference retrieval and writing.

For the grouping, first students group themselves according their individual feeling. The left are then grouped by their major and grade. Maybe this is the most effective way. Individual will is the point required to be considered in advance so that they have mutual understanding and the groups would have greater cohesion. However, some reference standards should be provided for them: (1) it is best to have at least one member of mathematics department in each team; (2) there must be at least one who is familiar to mathematical software; (3) one of the members should be good at reference retrieval and paper writing; (4) there must be a team leader agreed by the team members; (5) if possible it is preferred to include a girl in each team; (6) the members of the team had better not be all sophomores. The guidelines are suitable to both free combinations and man-made groupings. 
For the counseling before the contest, the way of doing is training for two weeks in the summer holiday. Though the investigation of opinions of some trained students, the authors think this training may have positive factors but it may be little helpful for students. The training schedule is tight while the training contents are tediously complicated. On the one hand, it makes mathematical modeling unattractive, boring tedious. On the other hand, it makes students tired, perplexed and coward of mathematical modeling. The original intension is to remedy those new hands to obtain basic skills and knowledge to participate the contest. However, the students in department of mathematics have already mastered basic knowledge while the others are lack of basic knowledge. Besides, the students who are not under selection having uneven levels makes the training impractical not easy to reconcile. Meanwhile, both the teachers and students have cancelled their holidays. It would be better to leave the time to themselves, they learn and study according their own interests and decisions.

For the contest, the college provides computer room for the contest. Putting all the students into a large computer room has a lost of disadvantages. First, the environmental clutter noises including the players' discussion and the noises of computer running would affect the players' thinking. Second, the flow of air is not fluent, the players can not get brain excited, instead, sitting long term in that environment makes their thinking stagnate. A better improvement in hardware can improve the players' competition results. The improvement scheme of this aspect is still under consideration.

\section{Summary}

To cultivate the students' comprehensive quality is an important task of higher education while knowledge and abilities reflect their personal qualities. Mathematical modeling plays an important role in the cultivation of students' application ability based on mathematical application ability and professional knowledge. Mathematical modeling is also an effective way to cultivate students' divergent thinking and innovative ability. In the paper, the author has discussed and analyzed current problems and proposed how to solve them. In order to foster the students' quality, the training programs and teaching methods will be further optimized and improved.

\section{Acknowledgements}

This research was supported by Hainan Education Department (Grant No. Hjjg2013-32).

\section{References}

[1] Brian V. Merkey, David. L. Chopp, Modeling the impact of interspecific competition on performance of a Microbial Fuel Cell, Bulletin of Mathematical Biology, 76 (2014), 1429-1453.

[2] Feliksas Ivanauskas, Praas Katauskis, Vadas Laurinwvicius, Journal of Mathematical chemistry, 52 (2014), 689-702.

[3] O. V. Muravieva, D. S. Murashova, S. A. Murashow, Biomedical engineering, 48 (2014), 148-152.

[4] Jean. Frano, Mathematical modeling of volumetric material growth, 84 (2014), 9-11.

[5] Yitui Chen, Chungchiang Chen, The optimal reuse of reclaimed water: a mathematical model analysis, Water resources management, 2014.

[6] Daqian Li, China undergraduate mathematical contest in modeling, Higher Education Press, 2011.

[7]Informationonhttp://baike.baidu.com/link?url=iAeuuLL52jOj9RkLsqwLanX2wrst9mKqkslxP1r 1CoUmhkjrwkTvGpsUslZYO5NVCIkBkJa_Eu1Nmbp5njQUoK.

[8] Daqian Li, Melting mathematical modeling thinking into main mathematical courses, China college teaching, 1 (2006), 9-11. 
[9] Chengdong Wei, The Probe and Practice on Melting into Mathematical Modeling, Higher education forum, 4 (2008), 28-30.

[10] Xuelian Wen, the infilteration of the concept of mathematical modeling into the teaching of discrete mathematics, China scienece and technology information, 3 (2010), 236-238. 